\title{
Improving ICU Nurses' Practices of Physical Restraints in Jordan: Effect of an Educational Program
}

\author{
Heba Nasrate1, Aseel Shamlawi², Muhammad W. Darawad1 \\ ${ }^{1}$ School of Nursing, The University of Jordan, Amman, Jordan \\ ${ }^{2}$ Albasheer Hospital, Amman, Jordan \\ Email: hebanasrate@yahoo.com, aseel_sh86@hotmail.com,m.darawad@ju.edu.jo
}

How to cite this paper: Nasrate, H., Shamlawi, A. and Darawad, M.W. (2017) Improving ICU Nurses' Practices of Physical Restraints in Jordan: Effect of an Educational Program. Health, 9, 1632-1643.

https://doi.org/10.4236/health.2017.912120

Received: September 17, 2017

Accepted: November 12, 2017

Published: November 15, 2017

Copyright $\odot 2017$ by authors and Scientific Research Publishing Inc. This work is licensed under the Creative Commons Attribution International License (CC BY 4.0).

http://creativecommons.org/licenses/by/4.0/

\begin{abstract}
Background: Physical Restraint (PR) has been widely used in the intensive care units, which aims to protect patients and maintain their safety. With all benefits of PR, there are many complications and risks from improper utilization. Further, no Jordanian studies have found to educate nurses regarding the proper PR utilization. Purpose: To evaluate the impact of an educational program on nurses' knowledge, attitude and practice regarding PR use in ICUs. Methods: A pre-experiment with one-group pretest-posttest design was used among 40 ICU nurses. A self-administered questionnaire was used to evaluate nurses before the education program and two weeks after its completion. Results: After implementation of the program, nurses demonstrated a significant difference in knowledge scores between pretest $(\mathrm{M}=10.35 \pm 1.73)$ and posttest $(\mathrm{M}=13.30 \pm 1.47)(\mathrm{t}=9.92 ; \mathrm{df}=39 ; \mathrm{P}=0.000)$, attitudes scores $(\mathrm{M}=$ $27.90 \pm 2.79$ vs. $\mathrm{M}=30.40 \pm 2.32)(\mathrm{t}=4.61 ; \mathrm{df}=39 ; \mathrm{P}=0.000)$, and practice scores $(\mathrm{M}=36.85 \pm 1.98$ vs. $\mathrm{M}=40.52 \pm 1.60)(\mathrm{t}=11.59 ; \mathrm{df}=39 ; \mathrm{P}=0.000)$. Conclusion: Service-education program can improve ICU nurses' knowledge, and enhance their attitudes and practices towards physical restraint. Such improvement is expected to be reflected in improving the quality of care delivered to the patients, and decreasing complications of malpractice regarding physical restraint.
\end{abstract}

\section{Keywords}

Physical Restraint, Educational Program, ICU Nurses, Knowledge, Attitudes, Practice, Jordan

\section{Introduction}

Physical restraint (PR) is one of the most commonly used methods by nurses to 
limit patient's mobility, especially in acute and long term care. PR is defined as "any device, material or equipment attached to or near a person's body and which cannot be controlled or easily removed by the person and which deliberately prevents or is deliberately intended to prevent a person's free body movement to a position of choice and/or a person's normal access to their body" [1]. Although PR is considered one of the undesirable methods of treatment and it is associated to the ethical dilemmas in delivering patient care especially for elderly patients [2], it is still a common practice and it has a direct and indirect positive effects.

PRs are used in intensive care units (ICU) rather than other wards due to confusion and agitation of the patients that affect on their safety and risk for falling in the ICU [3]. In addition, a recent study reported major reasons for restraints includes "Behavioural/confused/violent" (65\%) and preventing falls (62\%) [4]. The prevalence of PR was 33\% - 68\% in ICU which was higher than Non-ICUs less than $30 \%$ [2]. Further, a previous study reported that the rate of using restraints is different among the ICUs, where it was higher in (12.6 to $50.1 \%$ ) medical ICU compared to ( 14.5 to $34 \%$ ) in surgical ICUs [5]. A more recent study reported a prevalence rate of as high as $75 \%$ in medical-surgical wards in a teaching hospital in Jamaica [6]. Conversely, the rate of using of PR is different based on patients' age category. For instance, patients were restrained at rates of $6 \%$ to $13 \%$, while patients aged 65 years or older were restrained at a higher rate (18\% to $22 \%$ ) [3]. Similarly, Tinetti et al. [7] found patients' characteristics such as disorientation, dependence on getting dressed and the use of antidepressants to be independently associated to rate of using restraints.

Phillips [8] suggested that $80 \%$ of ICU patients may experience some degree of agitation during their stay. Therefore, the use of different types of restraint (physical and chemical) is often seen as simple solutions for agitated patients in ICUs [9]. Also, Nirmalan and colleagues [10] reported that the use of chemical restraints such as anxiolytics and sedatives drugs to facilitate dealing with a patient has benefits in controlling patient's behaviors, although it is associated with the risk of sedation-related psychosis. On the other side, PR was used by applying devices on body parts or by changing the environment which leads to restrict movement from one area to another. This is seen as a mean for protection of patient rather than chemical restraints in this environment.

Restraints are used for patient-centered reasons to save the patient from harming himself and others. For example, PR is used to prevent therapy discontinuation, patient's falls and injuries, and to protect clients from removing tubes, drains, and medical equipment connected to their body [11]. On the other side, PRs are used for staff-centered reasons to assist in nursing care management in the situations of patients' confusion and wandering within shortage of nursing staff and wandering within shortage of nursing staff [12]. Further, PRs were occasionally performed for the convenience of the nursing staff rather than for the safety of the patients. PR rates were reduced with a higher staff number [13]. 
Although the use of PR is considered as a method of protection for the patient, it is still associated with physical, psychological, ethical and legal problems and could led to death as a result of inappropriate PR. For example, studies suggested that PR may harm the skin and cause pressure sore, muscular atrophy, nosocomial infection, constipation, incontinence, limb injury, contractures, depression, anger, decrease in physical, cognition state, increase agitation even death [14]. Also, PRs have an effect on patient and family emotions including detention, decreased self-esteem, individuality, increased anxiety and loneliness [15]. On the other hand, PRs have an effect on nurse's emotions, such blame and dissatisfaction when they apply it on their patients [16].

Nurses in the ICU are the key providers in the application of PR for patient's safety, especially with agitated patients when they attempt to remove invasive tubes and devices that already in place [17]. So, nurses should be aware about PR and it consequences regarding to the ethical and legal problems. A study that examined nurses' knowledge, practice, and associated attitudes toward using of PR among ICU nurses found that nurses had inadequate and fair overall knowledge of PR use and direct tasks related to appropriate use. However, there were a positive attitudes regarding PR use [16]. The authors also reported that the majority of nurses were not aware that patients had the right to refuse the use of PR. In contrast, if they were a patient, they personally should have the right to refuse or resist when restraints were placed on to them.

Another qualitative study explored nurse's experience regarding PR use and showed that nurse's decision was based on routine practice regarding to PR application rather than evidence based [18]. Therefore, Pellfolk et al. [19] reported that nursing education has a significant effect in improving knowledge with a higher mean differences in interventional group than control group (11.1 vs. 9.1) and reduce the use of physical restraints for interventional group about 31.3\% are free from restraints compared to control group only $3.6 \%$ in the follow up, but still no effect in reducing number of falls or use of psychoactive medication. Also, educational programs can protect nurses from falling in legal and/or criminal consequences. Meanwhile, Hooseinrezaee and colleagues [20] reported education program about PR use that enhanced clinical decisions and improve on quality of care delivered to patients. The results was similar to Choi and Kim [21] who reported a positive significant effect on practices after education program relating using PR after two or six weeks of the duration of educational program.

In Jordan, limited research studies have been conducted related to use of PR in ICU. Additionally, limited literature is available in Jordan regarding nurses' knowledge and attitudes toward PR and the effect of educational programs on their knowledge and clinical practice in that concern, especially in reducing patients' complications related to PR such as pressure sore, limb edema, restricted circulation, and skin laceration at restraint site [22]. The aim of this study is to evaluate the impact of a training program on nurses' knowledge, attitude and 
practice regarding $\mathrm{PR}$ use in ICUs.

Research hypotheses

1. Nursing staff who complete a PR educational program will demonstrate increased knowledge regarding $\mathrm{PR}$.

2. Nursing staff who complete a PR educational program will demonstrate better attitudes toward PR.

3. Nursing staff who complete PR educational program will demonstrate improved practice of PR instrument.

\section{Methodology}

Design and Setting: A pre-experiment with one-group pretest-posttest design was used. Nurses were evaluated at two times before the education program and two weeks after its completion. The study was conducted among Jordanian registered nurses who were working at ICU in a private educational hospital, which is one of the largest private hospitals in Amman, capital of Jordan, which contains 27 ICU beds.

Sampling: The target population of this study includes all Jordanian nurses working in Jordanian ICU departments. Accessible population was registered nurses working in the ICUs of the participating hospital. Inclusion criteria included Jordanian registered nurses, with a bachelor degree in nursing, and who had a clinical experience of at least three months in ICU and providing direct patient care were targeted in this study. Convenience sampling was utilized to recruit nurses working in all shifts. Forty three nurses agreed to voluntarily participate and granted consent. Three nurses withdrew from the study (one in maternity leave and two traveled outside Jordan), leaving a total sample size of 40 . According to previous studies which were conducted to evaluate the effect of educational programs on nurses' knowledge, attitude and practice regarding PR, a medium effect size was estimated. Sample size was calculated using G power statistical software, power 0.80 and significance level of 0.05 , with paired t test (2-tailed). Accordingly, a total of 38 were needed.

Instrument: The study package contained two parts, where part one contained nurses' demographic characteristics including age, gender, marital status, and years of experience in nursing after graduation. In addition, four questions were utilized regarding available policy in hospital related to PR, sources of nurses' information about $\mathrm{PR}$, major complications of $\mathrm{PR}$, and utilizing alternatives of PR used by ICU nurses. Part two consisted of The Physical Restraint Questionnaire developed by Janelli et al. [23], which is a self-administered questionnaire. This questionnaire was used to explore the effectiveness of an educational program on ICU nurses' knowledge, attitudes and practices regarding the use of PR among ICU patients. This study adopted the Arabic version translated by Azab and Negm [24].

The Physical Restraint Questionnaire has three sections; the first section consisted of 15 items to evaluate nurse's knowledge about the use of PR (definition, 
purposes, indications, methods, alternatives, safety measures, complications, etc.). This section uses a yes/no format with one grade for each correct answer and zero grade for each incorrect answer, while the question answered by "I don't know" was considered as incorrect. The total grade ranges from $0-15$, with higher scores indicate better knowledge.

The second section contained 11 items that evaluated nurses' attitudes towards the use of PR using a 3-point Likert scale from agree $=3$ to disagree $=1$, giving a score range from 11 -33, with higher scores indicating more positive attitudes. The last section evaluated nurses' compliance with recommended practices of PR using 14 procedures before the application of restraints, order for use, documentation for indication, observation, complication and follow up. This section uses a 3-point Likert scale ranging from always $=3$ to never $=1$ follow these practices. Higher scores reflect better practices, with the total score ranges from 14 - 42.

A pilot study was carried out to evaluate the clarity and understandability of the questionnaire before introducing it to the study participants, and to assess the feasibility of the study in terms of acceptability to the participants. It helped in detection of difficulties in 3 items and led to facilitate integration into the clinical setting. Therefore, nurses who participated in the pilot study were excluded in the main study sample.

Data Collection: After obtaining permission to conduct the study, researchers visited the target hospital and interviewed the head nurses of the ICU departments to illustrate the study purpose and procedure, and to seek their permission to conduct the study in their units. Then, nurses were interviewed to identify eligible nurses who have been invited to participate in the study. Informed written consent was obtained from staff participants prior to the collection of data. The consent form described study purpose, illustrated that participation was voluntary, and assured that all data would be used for research purposes only and will be kept confidential. Pretest questionnaire was distributed in clinical setting by researchers, after explanation about topic idea for head nurses and for participant nurses consist mainly from 6 - 7 nurses on multi times in work place. Participants' names and phone numbers were collected in separate sheet to contact them for post test. The self-administered questionnaire was distributed two times before and after intervention directly by the researchers to the participants.

The two day of the educational program took approximately two hours for about 5 - 7 nurses within their works place. The program included PR definition, purposes and types, emergency situation, general principles, staff responsibility, alternative interventions with side effect, documentation and policy highlight (Azab \& Negm, 2013; Evans et al., 2002). Also, a leaflet that contained all previous data supported by pictures was provided to the participants. Study was conducted over a 3-week period in hospital from March to May in 2016.

Ethical Consideration: Ethical permission was obtained from the Scientific 
Research Committee at the School of Nursing, the University of Jordan, and the participating hospital. Written consent form was obtained from nurses after explanation of the study objectives and procedure, clarification about posttest after two weeks was explained, participation was voluntary, with the possibility to withdraw also participation at any time without penalties, and confidentiality was assured, and decision to participate will not affect their working status, and the data will be used for research process only.

Statistical analysis: Data were analyzed using the Statistical Package for Social Sciences (SPSS-21.0). Descriptive statistics including Means, standard deviations and frequencies were used to describe participants' demographics, and the main study variables (both pre and post test). To evaluate the effectiveness of the educational program in promoting nurses' knowledge, attitude, and practices of PR, a series of paired t-tests were conducted to compare their values in pre and post test. Significant differences were considered at $\mathrm{p}$-value less than 0.05 .

\section{Results}

\subsection{Demographic Characteristics}

The participants in this study were 40 nurses who voluntarily agreed to participate and consented to participate. As seen in Table 1, the majority of the sample were females (60.0\%), aged less than 30 years old $(77.5 \%)$, with an experience of less than 5 years (77.5\%). Approximately (57.5\%) of nurses did not have previous training about $\mathrm{PR}$, about (87.5\%) of nurses used $\mathrm{PR}$ in frequently during last month. Only (35.0\%) of nurses were aware of the presence of policy in their hospital about PR as in Table 1. More than half of nurses (55\%) reported they faced incidence of complications from physical restraints, the main complication reported was nervousness about (42\%).

\subsection{Testing Research Hypotheses}

A series of paired t-test was used for testing study hypotheses in order to evaluate the effectiveness of the educational program in promoting nurses' knowledge, attitude and practice of PR. The first hypothesis was tested as shown in Table 2, where the difference in pre $(\mathrm{M}=10.35 \pm 1.73)$ and post $(\mathrm{M}=13.30 \pm$ 1.47) knowledge score was found to be statistically significant ( $\mathrm{t}=9.92$; $\mathrm{df}=39$; $\mathrm{P} \leq 0.01$ ). This result suggested the usefulness of implementing such programs to improve nurses' knowledge regarding PR.

Testing the second hypothesis (Table 3) showed that the difference in pre participants' attitudes score $(\mathrm{M}=27.90 \pm 2.79)$ in opposition to the post participants' attitudes scores $(\mathrm{M}=30.40 \pm 2.32)$ after implementation of PR educational program was statistically significant $(\mathrm{t}=4.61 ; \mathrm{df}=39 ; \mathrm{P}<0.01)$, which suggested that such educational programs have an effect on improving nurses' attitudes' regarding PR. Similarly, the educational program showed effectiveness in improving nursing practice PR (Table 4) as they demonstrated a higher practice scores after exposure to the educational program $(\mathrm{M}=40.52 \pm 1.60)$ in comparison 
Table 1. Participants' demographic characteristic $(\mathrm{N}=40)$.

\begin{tabular}{|c|c|c|}
\hline Items & Frequency & $\%$ \\
\hline \multicolumn{3}{|l|}{ Age (years) } \\
\hline$<30$ & 31 & 77.5 \\
\hline$\geq 30$ & 9 & 22.5 \\
\hline \multicolumn{3}{|l|}{ Gender } \\
\hline Female & 24 & 60.0 \\
\hline Male & 16 & 40.0 \\
\hline \multicolumn{3}{|l|}{ Work Experience (years) } \\
\hline$<5$ & 31 & 77.5 \\
\hline $5-10$ & 6 & 15.0 \\
\hline$>10$ & 3 & 7.5 \\
\hline \multicolumn{3}{|l|}{ Training on $\mathrm{PR}$} \\
\hline Yes & 17 & 42.5 \\
\hline No & 23 & 57.5 \\
\hline \multicolumn{3}{|l|}{ Knowing about PR policy } \\
\hline Yes & 14 & 35.0 \\
\hline No & 26 & 65.0 \\
\hline \multicolumn{3}{|c|}{ Incidence of complications from PR } \\
\hline Yes & 22 & 55 \\
\hline No & 18 & 45 \\
\hline \multicolumn{3}{|l|}{ Main complication from PR } \\
\hline Skin ulcer & 6 & 15.0 \\
\hline Nervousness & 17 & 42.5 \\
\hline Muscle atrophy & 2 & 5.0 \\
\hline Hemodynamic Alteration & 4 & 10.0 \\
\hline
\end{tabular}

Table 2. Differences pre-post knowledge scores regarding to educational program $(\mathrm{N}=$ 40).

\begin{tabular}{cccccc}
\hline \multirow{2}{*}{ Pair 1 } & \multicolumn{2}{c}{ Paired Differences } & & df & P \\
\cline { 2 - 3 } & Mean & Std. Error Mean & & & \\
\hline Knowledge & & & -9.92 & 39 & 0.000 \\
Pre-experimental & 10.35 & 0.30 & & \\
Post-experimental & 13.30 & & & \\
\hline
\end{tabular}

${ }^{*}$ Significant at $\alpha=0.05$ (2-tailed), using paired sample $t$-test.

Table 3. Differences pre-post Attitude scores regarding to educational program $(\mathrm{N}=40)$.

\begin{tabular}{ccccccc}
\hline & \multicolumn{2}{c}{ Paired Differences } & & df & P \\
\cline { 2 - 3 } & Mean & Std. Error Mean & & & \\
\hline Attitude & & & & & \\
Pre-experimental & 27.90 & 0.54 & -4.61 & 39 & 0.000 \\
Post-experimental & 30.40 & & & & \\
\hline
\end{tabular}

${ }^{\star}$ Significant at $\alpha=0.05$ (2-tailed), using paired sample $t$-test. 
Table 4. Differences pre-post practice scores regarding to educational program $(\mathrm{N}=40)$.

\begin{tabular}{|c|c|c|c|c|c|}
\hline \multirow{2}{*}{ Pair 3} & \multicolumn{2}{|c|}{ Paired Differences } & \multirow{2}{*}{$t$} & \multirow{2}{*}{ df } & \multirow{2}{*}{$p$} \\
\hline & Mean & Std. Error Mean & & & \\
\hline Practice & & & & & \\
\hline Pre-experimental & 36.85 & 0.32 & -11.59 & 39 & 0.000 \\
\hline Post-experimental & 40.52 & & & & \\
\hline
\end{tabular}

*Significant at $\alpha=0.05$ (2-tailed), using paired sample $t$-test.

to pre practice scores $(M=36.85 \pm 1.98)$. These findings confirm a statistically significant difference in scores $(t=11.59 ; \mathrm{df}=39 ; \mathrm{P}<0.01)$ and suggest the usefulness of implementing such programs to improve nurses' practices regarding application PR.

\section{Discussion}

This is an interventional study that aimed to explore the impact of an educational program on ICU nurses' knowledge, attitude and practice regarding use of PR, which would increase their knowledge and if it had a beneficial positive effect on improvement their practice among restrained patients in ICUs. Such a study can aid in improving the quality of nursing care for patients in Jordanian ICUs who were found to have many problems including suffering from unnecessary pain [25] and inadequate nursing education [26]. Similarly, Jordanian nurses are in need for such education programs that enhance their practice as they were noticed to have less than optimal in different areas of nursing care including handwashing [27] and enteral nutrition [28].

The findings of this study demonstrated significant improvement in general level of knowledge, attitude and practice regarding PR use among ICU nurses, which leads to accept the set hypotheses regarding impact of educational program. The current study involved a sample of 40 nurses, $57 \%$ of them did not take any PR educational programs and more than half of them did not know if there hospital has PR policy that should integrate it in PR educational programs. As Cannon and colleagues [29] found that the majority of nurses did not obtain any particular learning or in-service preparation about $P R$, which negatively affected on nurses practices. Also, Chien and Lee [30] reported the integration of restraint policy in private hospitals within strict regulations and observe how nurses follow these regulations that affected nurses attitudes and their practices regarding $P R$ use in acute settings.

The current study reflects a positive significant effect on enhancement in nurses' knowledge after implementation two hour in-service education programs. The difference in pre knowledge scores and post knowledge scores among group after implementation of the PR educational program was statistically significant. This finding was similar to the majority of educational programs results in this field. Huang and colleagues [31] conducted a 90-minute in-service education program in Taiwan. After two weeks, participants showed 
significant improvement in their knowledge that play a main role in reducing PR use. Similarly, Choi and Kim [21] measured the improvement six weeks after the educational program and found significant improvement in nurses' knowledge. The results of our study recommend that there is a need to evaluate the long-term effects of the intervention on patient care related to PR use in critical care setting in the future.

The study demonstrated significant improvement in practice part related to PR by slightly increasing their mean from 63.9 to 40.5 . This is considered a slight improvement but was statistically significant. The result was analyzed after two weeks of educational program. This was congruent with Taha and Ali [32] who observed the practice of nurses after educational program but without studying the affect of their practice on patients' outcome by decreasing the complications. Conversely, the result of current study was incongruent Choi and Kim [21] who reported no statistically significant differences after education program on practices relating PR after six weeks of intervention, while Hooseinrezaee et al. [20] assured that educational programs may be conducted to get better practice, reach proper attitude and increase nurses' knowledge.

Regarding participant s' attitudes toward using of PR significantly improved by increasing in the mean from 27.9 to 30.4 . This improvement is similar to Hooseinrezaee et al. [20] and Huang et al. [31]. On the other hand, our study was incongruent with Choi and Kim [21] who found no statistically significant differences in attitude between control and interventional group. The current study supported the positive relation between knowledge improvement and attitude enhancement.

Our study suggests we need focusing on nurses' learning about of PR. This knowledge improvement will affect the quality of practice and care delivered to the patients. Actually, Jordanian nurses are in need for such programs of different nursing aspects, and showed that they benefit from them [33] [34] [35], and would increase their commitment to their profession [36]. However, we recommend the future studies to investigate the influence of enhancement in nurses' knowledge and practice on patients' outcomes associated to physical restraining. Finally, increasing ICU nurses' autonomy is also recommended that would have benefits for both nurses and patients [37].

Limitations of the Study: A convenience sample was utilized and quasi-experimental one group pre-post test design was used in the current study. In addition, our small sample size (40 nurse) drawn from a single hospital might limit the generalizability of our results. Thus, the external validity of the findings is limited. Farther studies are needed by using randomized controlled design with interventional and control group and conducting study to different types of hospital (military, governmental and private) not only on a private hospital, all of this will improve the generalizability of study results to all Jordanian nurses and allow to measure the effect of educational program more accurately. Current study used only one type of education as lecture, while other type of education 
can be introduced to yield for more benefits, we recommend using other methods like video and training session and followed by examine long term effects of PR educational program.

\section{Conclusion}

This study was carried out to test the hypotheses that implementing educational program for training nurses in their using PR would improve their related knowledge, attitude and practice in ICUs. Study findings reflect that the educational program was used to improve intensive care units nurses' knowledge, and also enhance the attitude and practice toward PR. This means that the wrong practices or misconception that would extend to nurses will be perpetual. From this result, hospitals administration can recommend to continuous education department to introduce in service-education program related to $\mathrm{PR}$ in annual curricula, and also recommend for quality department to initiate policy regarding to PR use.

\section{Acknowledgements}

Sincere thanks to the participants and to the director of nursing within the participating hospital for their time and support.

\section{References}

[1] Gastmans, C. and Milisen, K. (2006) Use of Physical Restraint in Nursing Homes: Clinical-Ethical Considerations. Journal of Medical Ethics, 32, 148-152. https://doi.org/10.1136/jme.2005.012708

[2] Goethals, S., De Casterlé, B.D. and Gastmans, C. (2013) Nurses' Ethical Reasoning in Cases of Physical Restraint in Acute Elderly Care: A Qualitative Study. Medicine, Health Care and Philosophy, 16, 983-991. https://doi.org/10.1007/s11019-012-9455-Z

[3] Minnick, A.F., Mion, L.C., Johnson, M.E., Catrambone, C. and Leipzig, R. (2007) Prevalence and Variation of Physical Restraint Use in Acute Care Settings in the US. Journal of Nursing Scholarship, 39, 30-37. https://doi.org/10.1111/j.1547-5069.2007.00140.x

[4] Shin, A.Y., Aloweni, F.A.B., Perera, K., Wee, S.L., Manickam, A., Lee, J.H.M., et al. (2015) Physical Restraints among the Elderly in the Acute Care Setting: Prevalence, Complications and Its Association with Patients' Characteristics. Proceedings of Singapore Healthcare, 24, 137-143. https://doi.org/10.1177/2010105815596092

[5] Martin, B. and Mathisen, L. (2005) Use of Physical Restraints in Adult Critical Care: A Bicultural Study. American Journal of Critical Care, 14, 133-142.

[6] Barton-Gooden, A., Dawkins, P.E. and Bennett, J. (2013) Physical Restraint Usage at a Teaching Hospital: A Pilot Study. Clinical Nursing Research.

[7] Tinetti, M., Liu, W., Marottoli, R. and Ginter, S. (2015) Mechanical Restraint Use among Residents of Skilled Nursing Facilities: Prevalence, Patterns, and Predictors. JAMA, 265, 468-471. https://doi.org/10.1001/jama.1991.03460040044026

[8] Phillips, K. (2013) Behavior Intervention-Seclusion \& Restraints. In: Bader, K., Ed., Argumentative Essay, Restraints, EBSCO Publishing Inc. 
[9] Langley, G., Schmollgruber, S. and Egan, A. (2011) Restraints in Intensive Care Units: A Mixed Method Study. Intensive and Critical Care Nursing, 27, 67-75. https://doi.org/10.1016/j.iccn.2010.12.001

[10] Nirmalan, M., Dark, P.M., Nightingale, P. and Harris, J. (2004) Editorial IV Physical and Pharmacological Restraint of Critically Ill Patients: Clinical Facts and Ethical Considerations. British Journal of Anesthesia, 92, 789-792. https://doi.org/10.1093/bja/aeh138

[11] Benbenbishty, J., Adam, S. and Endacott, R. (2010) Physical Restraint Use in Intensive Care Units across Europe: The PRICE Study. Intensive and Critical Care Nursing, 26, 241-245. https://doi.org/10.1016/j.iccn.2010.08.003

[12] Evans, D., Wood, J., Lambert, L. and Fitzgerald, M. (2002) Physical Restraint in Acute and Residential Care: A Systematic Review Number 22. Joanna Briggs Institute for Evidence Based Nursing \& Midwifery, Adelaide.

[13] De Jonghe, B., Constantin, J., Chanques, G., Capdevila, X., Lefrant, J. and Mantz, J. (2013) Physical Restraint in Mechanically Ventilated ICU Patients: A Survey of French Practice. Intensive Care Medicine, 39, 31-37. https://doi.org/10.1007/s00134-012-2715-9

[14] Mion, L.C. (2008) Physical Restraint in Critical Care Settings: Will They Go Away? Geriatric Nursing, 29, 421-423. https://doi.org/10.1016/j.gerinurse.2008.09.006

[15] Strout, T.D. (2010) Perspectives on the Experience of Being Physically Restrained: An Integrative Review of the Qualitative Literature. International Journal of Mental Health Nursing, 19, 416-427. https://doi.org/10.1111/j.1447-0349.2010.00694.x

[16] Janelli, L.M., Stamps, D. and Delles, L. (2006) Physical Restraint Use: A Nursing Perspective. MEDSURG Nursing, 15, 163-167.

[17] Chang, B., Yang, Y., Chang, L., Lee, Y. and Li, Y. (2006) A Study on Knowledge, Attitude, and Practice of Physical Restraints for Critical Care Nurses. Taiwan Criticai Care Medicine, S, 1-11.

[18] Hantikainen, V. and Käppeli, S. (2000) Using Restraint with Nursing Home Residents: A Qualitative Study of Nursing Staff Perceptions and Decision-Making. Journal of Advanced Nursing, 32, 1196-1205. https://doi.org/10.1046/j.1365-2648.2000.01590.x

[19] Pellfolk, T., Gustafson, Y., Bucht, G. and Karlsson, S. (2010) Effects of a Restraint Minimization Program on Staff Knowledge, Attitudes, and Practice: A Cluster Randomized Trial. Journal of the American Geriatrics Society, 58, 62-69. https://doi.org/10.1111/j.1532-5415.2009.02629.x

[20] Hooseinrezaee, H., Nouhi, E. and Taher, S. (2015) The Effect of Education on Trauma Critical Care Nurses Attitudes towards and Knowledge and Practices from the Viewpoint of Their about Application of Physical Restraint. Journal of Nursing Education, 4, 31-38.

[21] Choi, K. and Kim, J. (2009) Effects of an Educational Program for the Reduction of Physical Restraint Use by Caregivers in Geriatric Hospitals. Journal of Korean Academy of Nursing, 39, 769-780. https://doi.org/10.4040/jkan.2009.39.6.769

[22] Kandeel, N.A. and Attia, A.K. (2013) Physical Restraints Practice in Adult Intensive Care Units in Egypt. Nursing \& Health Sciences, 15, 79-85. https://doi.org/10.1111/nhs.12000

[23] Janelli, L., Kanski, G., Scherer, Y. and Neary, M. (1992) Physical Restraints: Practice, Attitudes/Knowledge among Nursing Staff. Journal of Long Term Care Administration; 20, 22-25. 
[24] Azab, S. and Negm, L. (2013) Use of Physical Restraint in Intensive Care Units (ICUs) at Ain Shams University Hospitals, Cairo. Journal of American Science, 9, 230-240.

[25] Darawad, M., Al-Hussami, M., Saleh, A., Al-Sutari, M. and Mostafa, W. (2014) Predictors of ICU Patients' Pain Management Satisfaction. Australian Critical Care, 28, 129-133. https://doi.org/10.1016/j.aucc.2014.07.003

[26] Mosleh, S., Eshah, N. and Darawad, M. (2016) Percutaneous Coronary Intervention and Heart Surgery Learning Needs of Patients in Jordan. International Nursing Review, 63, 562-571. https://doi.org/10.1111/inr.12318

[27] Al-hussami, M., Darawad, M. and Almhairat, I. (2011) Predictors of Compliance Handwashing Practice among Healthcare Professionals. Healthcare Infection, 16, 79-84. https://doi.org/10.1071/HI11004

[28] Darawad, M., Hammad, S., Al-hussami, M., Haourani, E., Aboshaiqah, A. and Hamdan-Mansour, A.M. (2015) Investigating Critical Care Nurses' Perception Regarding Enteral Nutrition. Nurse Education Today, 35, 414-419. https://doi.org/10.1016/j.nedt.2014.11.023

[29] Cannon, M.E., Sprivulis, P. and Mccarthy, J. (2001) Restraint Practices in Australasian Emergency Departments. Australian and New Zealand Journal of Psychiatry, 35, 464-467. https://doi.org/10.1046/j.1440-1614.2001.00925.x

[30] Chien, W. and Lee, I. (2007) Psychiatric Nurses' Knowledge and Attitudes toward the Use of Physical Restraint on Older Patients in Psychiatric Wards. International Journal of Multiple Research Approaches, 1, 52-71. https://doi.org/10.5172/mra.455.1.1.52

[31] Huang, H.T., Chuang, Y.H. and Chiang, K.F. (2009) Nurses' Physical Restraint Knowledge, Attitudes, and Practices: The Effectiveness of an In-Service Education Program. Journal of Nursing Research, 17, 241-248. https://doi.org/10.1097/JNR.0b013e3181c1215d

[32] Taha, N.M. and Ali, Z.H. (2013) Physical Restraints in Critical Care Units: Impact of a Training Program on Nurses' Knowledge and Practice and on Patients' Outcomes. Journal of Nursing \& Care, 2, 135.

[33] Al-hussami, M., Saleh, M., Darawad, M. and Alramli, M. (2011) Evaluation of the Effectiveness of Nursing Clinical Training Preceptorship Program. Journal of Continuing Education in Nursing, 42, 569-576. https://doi.org/10.3928/00220124-20110901-01

[34] Toubasi, S., Alosta, M., Darawad, M. and Demeh, W. (2015) Impact of Simulation Training on Jordanian Nurses' Performance of Basic Life Support Skills: A Pilot Study. Nurse Education Today, 35, 999-1003. https://doi.org/10.1016/j.nedt.2015.03.017

[35] Yacoub, M., Demeh, W., Darawad, M., Saleh, M. and Saleh, A. (2015) Outcomes of Diabetes Educational Program for Registered Nurses Caring for Persons with Diabetes. Journal of Continuing Education in Nursing, 46, 129-133. https://doi.org/10.3928/00220124-20150126-02

[36] Saleh, A., Darawad, M. and Al-Hussami, M. (2014) Organizational Commitment and Work Satisfaction among Jordanian Nurses: A Comparative Study. Life Science Journal, 11, 31-36.

[37] Maharmeh, M., Alasad, J., Salami, I., Saleh, Z. and Darawad, M. (2016) Clinical Decision-Making among Critical Care Nurses: A Qualitative Study. Health, 8, 1807-1819. https://doi.org/10.4236/health.2016.815173 